-ORIGINAL ARTICLE-

Volume 13 Issue 42021

DOI: 10.21315/eimj2021.13.4.4

ARTICLE INFO

Received: 06-10-2021

Accepted: 23-07-2021

Online: 30-12-2021

\section{Knowledge Acquisition and Satisfaction of Virtual Microscopy Usage Among Medical Students of Universiti Sains Malaysia}

\author{
Anna Alicia Simok', Fazlina Kasim', Siti Nurma Hanim Hadie', \\ Husnaida Abdul Manan@Sulong², Muhamad Saiful Bahri Yusoff', \\ Nor Farid Mohd Noor ${ }^{3}$, Mohd Asnizam Asari' \\ ${ }^{1}$ Department of Anatomy, School of Medical Sciences, Universiti Sains \\ Malaysia, Kelantan, MALAYSIA \\ ${ }^{2}$ Integrative Medicine Cluster, Advanced Medical and Dental Institute, \\ Universiti Sains Malaysia, Pulau Pinang, MALAYSIA \\ ${ }^{3}$ School of Dental Sciences, Universiti Sains Malaysia, Kelantan, \\ MALAYSIA \\ ${ }^{4}$ Department of Medical Education, School of Medical Sciences, \\ Universiti Sains Malaysia, Kelantan, MALAYSIA
}

To cite this article: Simok AA, Kasim F, Hadie SNH, Abdul Manan@Sulong H, Yusoff MSB, Mohd Noor NF, Asari MA. Knowledge acquisition and satisfaction of virtual microscopy usage among medical students of Universiti Sains Malaysia. Education in Medicine Journal. 2021;13(4):43-55. https://doi.org/10.21315/eimj2021.13.4.4

To link to this article: https://doi.org/10.21315/eimj2021.13.4.4

\begin{abstract}
The virtual microscope has been employed as an adjunct tool to teach optical microscopy for histology learning in medical schools. However, there is no reliable evidence in the literature that virtual and optical microscopy impacts students' learning. This study focuses on comparing two different methods in learning histology in Universiti Sains Malaysia, namely virtual microscopy and optical microscopy, with regard to medical students' knowledge acquisition and satisfaction levels. A total number of 120 medical students, consisting of 53 first-year and 67 second-year students, were recruited. The students were divided into virtual microscopy and optical microscopy groups. During the one-day intervention, all students attended a pre-requisite lecture on "Histology of the Eye", a slide demonstration and a hands-on session using a designated microscope. Students' knowledge acquisition was evaluated through a pre- and post-practical evaluation and their satisfaction level on learning histology using respective learning tools was measured. The study revealed that the optical and virtual microscopy groups showed significant improvement from the pre- to post-practical tests scores with $p<0.001$, respectively. However, the mean increment was higher in virtual microscopy $(38.51 \%)$ than in optical microscopy (35.08\%). Furthermore, the virtual microscopy group had a significantly higher satisfaction score towards the learning tool than the optical microscopy group, $p=0.008$. The knowledge acquisition of the virtual microscopy group was equal to the optical microscopy group as they were shown to have a similar improvement in the test scores, comprehension level and learning ability. However, students were nonetheless satisfied with the usage of virtual microscopy as a learning tool.
\end{abstract}

Keywords: Knowledge acquisition, Satisfaction, Virtual microscopy, Histology teaching and learning

CORRESPONDING AUTHOR Fazlina Kasim, Department of Anatomy, School of Medical Sciences, Health Campus, Universiti Sains Malaysia, 16150 Kubang Kerian, Kota Bharu, Kelantan, Malaysia

Email: fazlinakb@usm.my

(C) Malaysian Association of Education in Medicine and Health Sciences and Penerbit Universiti Sains Malaysia. 2021 This work is licensed under the terms of the Creative Commons Attribution (CC BY) (http://creativecommons.org/licenses/by/4.0/). 


\section{INTRODUCTION}

Histology teaching in the medical curriculum has undergone tremendous changes over the past decade (1). For centuries, histology teaching in medical schools was delivered through lectures and practical sessions, which involve handson exposure to optical microscopy (1). Nevertheless, the advent of the digitalisation era and the fourth industrial revolution has significantly influenced learning materials for teaching and learning histology, as they are digitalised using virtual microscopes (2). Since its inception in 2002, virtual microscopy has been used worldwide in many universities as a learning tool $(1,3)$. This tool was introduced in the medical histology curriculum to address a common problem in anatomy education, and it has reduced teaching contact hours $(1,4)$.

Arguably, a shortened practical duration has limited students' opportunity to learn histology using optical microscopy (1). Students crammed in one or more laboratories for a session that may simultaneously cover two to three histology topics as practical contact time is reduced. The availability of optical microscopy and histology slides will possibly become an issue for such a large community of students. One microscope and a set of slides must be shared by small groups of students, limiting them to navigate each slide at their own speed during the practical hours (5). While the new medical curriculum provides more time for student self-learning, optimising this extra time depends on the availability of learning resources and the microscope as a learning tool for histology in that context. A readily accessible learning tool will assist in self-learning period optimisation (5).

Likewise, histology teaching in Universiti Sains Malaysia (USM) is delivered through lectures and practical sessions. A demonstration is given by a qualified lecturer during the practical sessions using the virtual microscope. Following the demonstration, students take turns using the conventional optical microscope individually. At present, two students share an optical microscope during the practical sessions, while a box of slides is shared by 10 to 12 students. Given this condition, the optical microscope requires frequent maintenance and damage repair is costly. Furthermore, the glass slides wear out throughout time, and a new slide needs to be purchased and replaced if broken. These challenges support the fact that there are drawbacks of using optical microscopy in learning histology, as reported by many articles $(1,6-7)$.

Compared to the expense of keeping many optical microscopes and histology slide sets, the use of virtual microscopy in large groups of students was shown to be financially beneficial (7). Besides, virtual microscopy could prevent the occurrence of some health-related issues linked with the use of optical microscopes, such as motion sickness and eye fatigue (6). Virtual microscopy is also portable, easily accessible and can be conveniently used whenever a computer is available. It is noteworthy to highlight that students prefer easy access to their learning tool during and after formal classes for their subsequent revision (8-9). The factors mentioned above make virtual microscopy to be logistically more favourable in the long run.

Virtual microscopy, like any other teaching tool, has its limitations. It lacks the 3-dimensionality of optical microscopes through which students can change the focus planes by turning their focus knobs. As a result, students lose their sense of the dimension when viewing the slides. Low magnification provides less resolution when viewing is done on a regular computer screen. According to reports (10), original glass slide tissue artefacts and defects are harder to scan. If the quality of the original slide is good, the digital scanning will yield amazing photographs. As a result, it is critical to choose the highest-quality sections with acceptable staining, flat mounting and no artefacts (11). Another drawback of 
virtual microscopy is that the virtual slides take up tremendous memory, necessitating a great storage system (11).

Debate is still ongoing about the effectiveness of virtual microscopy as a learning tool compared to optical microscopy, while evidence supporting its effects is quite scarce and inconsistent (1). A randomised controlled crossover trial conducted at Ghent University, Belgium, reported no significant difference in the test results between two groups of students exposed to virtual and optical microscopes (12). Neither the type of microscope nor the order of use of these microscopes appears to affect the adequate transfer of histological knowledge to students (12). Contrary to this, another study conducted at Third Military Medical University, China, showed a substantial improvement in test scores among the virtual microscopy group compared to those of the optical microscopy group (13). These inconsistent findings warrant a more systematic assessment of the effectiveness of virtual microscopy in promoting learning for the students.

In general, students' task performance is an outcome measure for effective instructional design and delivery, and it is often coined under the knowledge acquisition construct (14-15). In a broad sense, knowledge acquisition is a process of obtaining information from external sources, and this concept has been used widely in the development of artificial intelligence through the construction of the expert system solution (16). Nevertheless, the theoretical basis of knowledge acquisition is stemmed from the concept of the human memory system, whereby new information is obtained from the external environment; processed by the human working memory; and saved in the long term memory which eventually can be retrieved for future learning (17-19). Hence, knowledge acquisition measures could be reflected by test score measures, task performance and learners' ability to learn (i.e., learnability)
- as these variables involve information processing, storage and retrieval $(14,20-$ 21).

The present study intends to compare the impact of virtual microscopy versus optical microscopy on students' knowledge acquisition in terms of comprehension level, improvement of knowledge and learning ability. Besides that, this study also assessed students' satisfaction level towards virtual microscopy as a learning tool. In general, students' satisfaction can be described as a short-term attitude resulting from educational experience assessment, services and facilities provided to the students (22). Over the past decades, students' satisfaction was subjectively measured. However, eventually, educationists began to specify some objective satisfaction measures according to specific models (22). A study by Dhaqane and Afrah claims that students' level of contentment reflects students' satisfaction during learning, which indirectly reflects the effectiveness of the education programme or instructional material that they experience (23). In addition, satisfaction can be considered an act of satisfying the desire to achieve the desired goals; and this is often correlated with academic success in a learning context (23).

Students' satisfaction towards a learning tool is a crucial factor for choosing the optimum tool for histology learning. Another research that compared the level of student satisfaction between using virtual microscopy and optical microscopy showed that most students viewed virtual microscopy as a technically focused teaching method that could improve learning (24). Despite many published studies on students' opinions about histology learning tools, data on students' satisfaction levels are still very limited $(5,25)$. Hence, the findings of this study will shed new light on how the students perceived the use of microscopes as a learning tool $(5,25)$. 


\section{MATERIALS AND METHODS}

\section{Study Design, Sampling Method and Study Subjects}

A randomised controlled study was conducted on 120 pre-clinical years (firstand second-year) medical students of the School of Medical Sciences, Universiti Sains Malaysia (USM). Purposive sampling was applied in this study. To participate in this research, students must not have repeated any subject, and their age should be between 18 and 25 years old when the study was conducted. Prior to the recruitment process, all pre-clinical year medical students were invited to attend a session in which a brief was given on the purpose, methodology, participation criteria, risks and benefits of the study. Written consent was obtained from students who were eligible and willing to participate in this study. This study had also received ethical approval from the Human Research Ethics Committee, USM.

\section{Sample Size and Group Allocation}

The sample size was estimated using the Cohen Statistical Power Analysis (behavioural sciences) table with a significance level $(\alpha)$ set at 0.05 , medium effect size and power of study of $80 \%$. The calculated sample size was 64 subjects per group or 128 subjects in total. A total of 157 students agreed to participate in the study. However, only 120 students completed the data collection process.

\section{Research Groups}

Group allocation was accomplished using a stratified random method to control confounding factors, namely gender and year, which may affect the study. The participants $(n=157)$ were grouped into four name lists, the first-year male students $(n=24)$, first-year female students $(n=$ $65)$, second-year male students $(n=26)$ and second-year female students $(n=42)$. Students were selected from each list to represent the optical microscopy group using the random number generator, and the remaining participants represented the virtual microscopy group. All participants had experienced using optical microscopes during previous histology practical sessions in the scheduled formal academic curriculum.

\section{Research Tool}

Each student in the optical microscopy group was given a compound light microscope (Nikon Instruments Inc). Meanwhile, the virtual microscopy group used the Pannoramic viewer, a virtual microscope software by 3DHISTECH Ltd. The histology glass slides of the iris and eyeball used in this study were from GinkgoMed Company, Taiwan and were all stained using hematoxylin and eosin (H\&E). The virtual slides were generated from representative slides of the iris and eyeball photographed at 40 times magnification using a slide scanner (Zeiss Mirax Desk, Germany). The pre-practical and postpractical questions were in the form of objective structured practical examination (OSPE) that contained five photographedaccompanied questions. The questions evaluated students' ability to identify different types of tissue of the iris and eyeball and their characteristic histological features. These questions were vetted by four trained histologists and one medical educationist. Student's satisfaction was measured using single-item questionnaires, which allowed students to score their satisfaction level using a five-point rating scale ( $1=$ very unsatisfied, $2=$ unsatisfied, $3=$ neutral, $4=$ satisfied, $5=$ very satisfied).

\section{The Intervention of the Study}

A one-day experiment was conducted on the weekend to avoid any intervention of students' formal academic programme. A topic that was not in the undergraduate anatomy syllabus was chosen as the learning content in this study, namely "Histology of the Eye", to remove the element of prior 
experience. Printed laboratory exercise booklets that contained a list of learning outcomes were given to all the students during registration.

The activity started with a one-hour lecture on eye histology by an experienced histology lecturer. All participants were then gathered to sit for a 30 minutes pre-practical evaluation in the laboratories. Immediately after, the same lecturer gave a 30 minutes slide demonstration session. Students were gathered in their assigned intervention group, either optical microscopy group or virtual microscopy group and escorted to their respective practical sessions. The optical microscopy group underwent a practical session in the optical microscope laboratory, and the virtual microscopy group attended a session in the computer laboratory.

During the one hour practical session, individual computers and three separate virtual slides were given to the students in the virtual microscopy group to view using the Pannoramic Viewer software. Prior to the session, they were given specific guidance on how to use the software, while each student from the optical microscopy group received an optical microscope for slide viewing purpose. However, two students of the optical microscopy group were made to share a set of slides, whereby each set having three histology slides similar to the virtual slides. A lecturer accompanied each group in their respective laboratories during the practicum session.

After the practical session, the students were reassembled at the optical microscope laboratory for post-practical evaluation. In the post-practical evaluation, the students answered five OSPE questions, followed by a survey that measured their satisfaction using the microscope for histology learning. Four outcome measures were quantified in this study, namely: a. Pre- and post-practical tests scores: These scores were measured prior to and after their practical sessions, respectively, and were presented in percentage. The pre-practical test scores reflected the students' baseline knowledge, while the postpractical test scores indicated the students' improvement in their comprehension.

b. Learning quotient score: Learning quotient is a measure of selfperceived learning ability (19). The scores were measured using the learning quotient equation proposed by Noda et al., in which 'a' denotes the percentage of correct answers in the pre-practical assessments, and ' $b$ ' indicates the percentage of correct answers in the post-practical assessments, respectively (26).

Learning quotient $(\mathrm{LQ})=[(\mathrm{b}-\mathrm{a})$

/ (100-a) $] \times 100$

c. Students' satisfaction score: The scores were used to assess the overall students' satisfaction with the learning method, given either the optical microscope or the virtual microscope in histology learning.

\section{Data Analysis}

The data analysis was conducted using Statistical Package for the Social Sciences (SPSS) software, version 24 (IBM Corp., Armonk, NY). The data were entered, tested, explored and cleaned for data entry errors and missing values. Before running the statistical test, assumptions were tested, and the significance level $(\alpha)$ was set at 0.05 with a $95 \%$ confidence interval. The statistical analyses were performed on the research data, namely independent $t$-test (pre-practical evaluation score), MannWhitney test (post-practical evaluation score, learning quotient score and students' satisfaction score) and paired $t$-test (change in the evaluation score). 


\section{RESULTS}

\section{Knowledge Acquisition Measurement}

\section{Comparison of the pre-practical test scores between study groups}

The pre-practical test scores of the two study groups were compared to determine the students' baseline knowledge regarding Histology of the Eye topic prior to the practical sessions as shown in Table 1 .
Our analysis showed no significant difference between the study groups in the pre-practical test scores, indicating that students in both groups had similar baseline knowledge about the histology topic.

\section{Comparison of the post-practical test scores between study groups}

Table 2 shows the comparative results of the post-practical test scores between the study groups in evaluating students' level of comprehension after their practical sessions.

Table 1: Comparison of the pre-practical test score between the study groups (27-28)

\begin{tabular}{|c|c|c|c|c|c|c|}
\hline \multirow[b]{2}{*}{ Variable } & \multicolumn{2}{|c|}{ Mean (SD) } & \multirow[b]{2}{*}{ t-statistics (df) } & \multirow[b]{2}{*}{$p$-value } & \multirow[b]{2}{*}{$\begin{array}{c}\text { Mean } \\
\text { difference } \\
(95 \% \mathrm{CI})\end{array}$} & \multirow[b]{2}{*}{$\begin{array}{l}\text { Cohen } \\
\text { effect } \\
\text { size (d) }\end{array}$} \\
\hline & $\begin{array}{c}\text { Virtual } \\
\text { microscopy } \\
\text { group } \\
(n=57)\end{array}$ & $\begin{array}{c}\text { Optical } \\
\text { microscopy } \\
\text { group } \\
(n=63)\end{array}$ & & & & \\
\hline $\begin{array}{l}\text { Pre- } \\
\text { practical } \\
\text { test score }\end{array}$ & $\begin{array}{c}43.789 \\
(22.584)\end{array}$ & $\begin{array}{l}38.714 \\
(23.199)\end{array}$ & $\begin{array}{c}-1.212 \\
(118)\end{array}$ & 0.228 & $\begin{array}{c}5.075 \\
(-13.368,3.217)\end{array}$ & 0.16 \\
\hline
\end{tabular}

Notes: Independent $t$-test was applied to determine mean difference between study groups. Significance level was set at $0.05 . \mathrm{SD}=$ standard deviation; $\mathrm{df}=$ degree of freedom; $\mathrm{Cl}=$ confidence interval. Cohen effect size was calculated using effect size calculator for $t$-test. Cohen effect size threshold: small $=0.20$, medium $=0.50$, large $=0.80$, very large $=1.13$.

Table 2: Comparison of the post-practical test score between the study groups (27-28)

\begin{tabular}{|c|c|c|c|c|c|}
\hline \multirow[b]{2}{*}{ Variable } & \multicolumn{2}{|c|}{ Median (IQR) } & \multirow[b]{2}{*}{ z-statistics } & \multirow[b]{2}{*}{$p$-value } & \multirow[b]{2}{*}{$\begin{array}{l}\text { Cohen effect } \\
\text { size }(d)\end{array}$} \\
\hline & $\begin{array}{l}\text { Virtual microscopy } \\
\text { group }(n=57)\end{array}$ & $\begin{array}{l}\text { Optical microscopy } \\
\text { group }(n=63)\end{array}$ & & & \\
\hline $\begin{array}{l}\text { Post-practical } \\
\text { test score }\end{array}$ & $\begin{array}{c}86 \\
(18.5)\end{array}$ & $\begin{array}{l}81 \\
(29)\end{array}$ & -1.935 & 0.053 & 0.43 \\
\hline
\end{tabular}

Notes: Mann-Whitney test was applied to determine difference between study groups. Significance level was set at 0.05 . $\mathrm{IQR}=$ Interquartile range. Cohen effect size was calculated using effect size calculator for $t$-test. Cohen effect size threshold: small $=0.20$, medium $=0.50$, large $=0.80$, very large $=1.13$.

The analysis showed no significant difference between the two groups concerning the post-practical test performance. The median of the postpractical test scores for the virtual microscopy group was not significantly higher than that for the optical microscopy group. This finding suggested that both research groups performed equally well in the post-practical test, reflecting an increase in their comprehension of the Histology of the Eye topic after attending their respective practical sessions. The Cohen effect size was calculated to determine the virtual microscopy's magnitude effect on the outcome. The Cohen effect size value of 0.43 reflected different types of microscopes usage had a borderline medium effect on students' histology knowledge comprehension. 


\section{Changes in test scores within each study group}

Changes in the test scores were assessed to determine the improvement of knowledge within each group, as shown in Table 3.

The mean scores of virtual and optical microscopy groups improved from $43.789 \%$ to $82.298 \%$ and $38.714 \%$ to $73.793 \%$, respectively. It was evident that the mean score difference of the virtual microscopy group was greater than that of the optical microscopy group. The results indicated that the test scores were increased significantly after the practical sessions for both virtual and microscopy groups. The measured Cohen effect size of both the virtual and optical microscopy groups, 1.83 and 1.75 respectively, were very high, suggesting that the substantial change in the test scores was most likely influenced by microscopy usage during histology learning.

Table 3: Changes in the test scores within group (27-28)

\begin{tabular}{|c|c|c|c|c|c|c|}
\hline \multirow[t]{2}{*}{ Group (n) } & \multicolumn{2}{|c|}{$\begin{array}{l}\text { Test score } \\
\text { mean (SD) }\end{array}$} & \multirow{2}{*}{$\begin{array}{c}\text { Mean } \\
\text { difference } \\
(95 \% \mathrm{Cl})\end{array}$} & \multirow[t]{2}{*}{ t-statistics (df) } & \multirow{2}{*}{$p$-value } & \multirow{2}{*}{$\begin{array}{l}\text { Cohen } \\
\text { effect size } \\
\text { (d) }\end{array}$} \\
\hline & Pre & Post & & & & \\
\hline $\begin{array}{l}\text { Virtual microscopy } \\
\text { group } \\
(n=57)\end{array}$ & $\begin{array}{c}43.789 \\
(22.583)\end{array}$ & $\begin{array}{c}82.298 \\
(16.368)\end{array}$ & $\begin{array}{c}38.508 \\
(32.926,44.091)\end{array}$ & $\begin{array}{c}13.818 \\
(56)\end{array}$ & $>0.001$ & 1.83 \\
\hline $\begin{array}{l}\text { Optical microscopy } \\
\text { group } \\
(n=63)\end{array}$ & $\begin{array}{c}38.714 \\
(23.198)\end{array}$ & $\begin{array}{c}73.793 \\
(22.621)\end{array}$ & $\begin{array}{c}35.079 \\
(30.035,40.123)\end{array}$ & $\begin{array}{c}13.902 \\
(62)\end{array}$ & $>0.001$ & 1.75 \\
\hline
\end{tabular}

Notes: Paired $t$-test was applied to determine the change in evaluation score within groups. Significance level was set at 0.05. $\mathrm{SD}=$ standard deviation; $\mathrm{df}=$ degree of freedom; $\mathrm{Cl}=$ confidence interval. Cohen effect size was calculated using effect size calculator for $t$-test. Cohen effect size threshold: small $=0.20$, medium $=0.50$, large $=0.80$, very large $=1.13$.

\section{Comparison of the learning quotient score between study groups}

The learning quotient scores were calculated using the pre-practical and post-practical tests scores by applying the aforementioned equation of learning quotient. The scores obtained reflected students' perceived ability in learning histology using the allocated microscopy, respectively. The research revealed that different types of microscopy did not affect students' perceived ability to learn histology as evidenced by no significant between-group difference of the learning quotient score and small Cohen effect size, as shown in Table 4.

Table 4: Comparison of the learning quotient score between study groups (27-28)

\begin{tabular}{|c|c|c|c|c|c|}
\hline \multirow[b]{2}{*}{ Variables } & \multicolumn{2}{|c|}{ Median (IQR) } & \multirow[b]{2}{*}{ z-statistics } & \multirow[b]{2}{*}{$p$-value } & \multirow[b]{2}{*}{$\begin{array}{l}\text { Cohen effect } \\
\text { size }(d)\end{array}$} \\
\hline & $\begin{array}{l}\text { Virtual microscopy } \\
\text { group }(n=57)\end{array}$ & $\begin{array}{l}\text { Optical microscopy } \\
\text { group }(n=63)\end{array}$ & & & \\
\hline $\begin{array}{l}\text { Learning } \\
\text { quotient score }\end{array}$ & $76.812(37.624)$ & $68.421(43.902)$ & -1.613 & 0.107 & 0.292 \\
\hline
\end{tabular}

Notes: Mann-Whitney test was applied to determine the difference between study groups. Significance level was set at 0.05 . IQR $=$ Interquartile range. Cohen effect size was calculated using effect size calculator for $t$-test. Cohen effect size threshold: small $=0.20$, medium $=0.50$, large $=0.80$, very large $=1.13$. 
This research did not indicate any significant difference in the learning quotient scores between the study groups. Although the learning quotient scores were higher in the virtual microscopy group than those in the control group - which indicated a higher perceived ability to learn by using the tool the Cohen effect size was small. Therefore, both the virtual microscopy and the optical microscopy groups showed a similar understanding of the histology topic after attending their respective practical sessions. Based on the estimated size of the Cohen effect, the intervention on the learning quotient scores brought small to medium effects $(d=0.29)$, which was possible because of their respective tools.

\section{Students' satisfaction score}

This study revealed a statistically significant difference in the students' satisfaction scores between different groups on the learning histology using difference microscopes. The results suggested that students were significantly pleased with the virtual microscope as a histology learning device. The calculated Cohen effect size was medium, indicating that the students' satisfaction with learning histology could have been moderately influenced by virtual microscopy usage in the intervention, as shown in Table 5.

Table 5: Comparison of student's satisfaction score between study groups (27-28)

\begin{tabular}{|c|c|c|c|c|c|}
\hline \multirow[b]{2}{*}{ Variable } & \multicolumn{2}{|c|}{ Median (IQR) } & \multirow[b]{2}{*}{ z-statistics } & \multirow[b]{2}{*}{$p$-value } & \multirow[b]{2}{*}{$\begin{array}{l}\text { Cohen effec } \\
\text { size }(d)\end{array}$} \\
\hline & $\begin{array}{l}\text { Virtual microscopy } \\
\text { group }(n=57)\end{array}$ & $\begin{array}{l}\text { Optical microscopy } \\
\text { group }(n=63)\end{array}$ & & & \\
\hline Satisfaction score & $5.00(1)$ & $4.00(2)$ & -2.654 & 0.008 & 0.50 \\
\hline
\end{tabular}

Notes: Mann-Whitney test was applied to determine the difference between study groups. Significance level was set at 0.05. IQR = Interquartile range. Cohen effect size was calculated using effect size calculator for $t$-test. Cohen effect size threshold: small $=0.20$, medium $=0.50$, large $=0.80$, very large $=1.13$.

\section{DISCUSSION}

This study attempted to explore the impact of virtual microscopy, a new teaching tool for histology learning, on students' knowledge acquisition and their satisfaction level. Although virtual microscopy is a sophisticated high-technology learning aid, the findings clearly indicated that virtual microscopy was not superior to its conventional counterpart, optical microscopy, in promoting knowledge acquisition. This study showed that both virtual and optical microscopes improved students understanding of histology knowledge, evidenced by the significant improvement in the test scores. Moreover, no differences were shown in students' knowledge comprehension and perceived ability to learn histology. This was proven by the insignificant difference of the post- practical test and learning quotient scores, respectively.

The recent pandemic has heightened the interest in virtual microscopy usage as a teaching tool in anatomy and histology education. The findings of the present study are concordant with those of Husmann et al., who explored the impact of virtual microscopy on students' laboratory test performance (7). The study revealed that students' laboratory examinations performance was significantly improved after being exposed to virtual microscopy during practical sessions for one year. Nevertheless, the findings of the present study are contrasted to a study by Krippendorf and Lough, who reported significantly higher laboratory examination scores of students who were exposed to virtual microscopy compared to previous 
batches of students, who were only exposed to optical microscopy during their practical sessions (25). This finding corroborates those of Felszeghy et al. who found that students who learned histology using a virtual microscope, incorporated with team-based learning pedagogy, obtained higher histology examination grades than those who learned through conventional slides demonstration using an optical microscope (29). Likewise, a randomised controlled study that evaluated the impact of virtual microscopy on histopathology undergraduate learning revealed significantly higher test scores among students who used virtual microscopy than those who used optical microscopy (30).

Nonetheless, several contradicting findings were found in the literature about the impact of virtual microscopy on students' test performance. Several past studies reported no significant difference between the post-laboratory test scores of students exposed to virtual microscopy and optical microscopy, respectively (9-12, 31-32). These studies reported several pertinent findings which reflected the advantages of using virtual microscopy. Ordi et al. reported that students perceived virtual microscopy as a user-friendly and convenient tool to be used anytime and anywhere as it provided easy navigation of tissue structures (9). Likewise, Donnelley et al. reported that virtual microscopy was well-appreciated by the students as it provided a new additional interactive feature that allowed students to annotate the histology slides during learning (32).

Hence, it could be argued that the findings of this study provided evidence that virtual microscopy had an influence on the knowledge acquisition construct of students. From a pedagogical point of view, knowledge acquisition is described as a process of gaining a new schema of information through experiences and experiments, which requires the brain to grasp, integrate, adapt and confirm learned information for constructing, understanding and reaching conclusions (33). Knowledge acquisition is interchangeably coined as learning, and it has been viewed in different educational theoretical aspects, namely behaviourism, cognitivism and humanism (33). Hence, measurement of knowledge acquisition can be classified as assessment of explicit knowledge (e.g., task performance, test scores and reasoning), implicit knowledge (e.g., knowledge transfer) and tacit knowledge, such as intuition, hunches, inherent talent, skills, experience and learning (ability) (33-34). In the present study, students' knowledge acquisition was evaluated via the test-score performance, and their learnability was evaluated via the learning quotient scores. These results reflected that students had gained some knowledge after using virtual microscopy as their learning tool in histology practicals. This postulation could be viewed in two aspects; students' ability to comprehend and identify tissue structures when using the virtual microscopy and students' ability to learn and adapt to the new learning environment as they had no experience using virtual microscopy. Concerning students' ability to acquire knowledge using virtual microscopy and optical microscopy, the findings showed similar results regardless of the different types of microscopy used.

In general terms, the learning quotient score, which represents the capacity of a person to learn new things (21) could be related to previous experience and deliberate practice. A study by Ericsson et al. showed that deliberate method improves an individual's performance and cognitive ability (35). The repetitive, purposeful practice of a learning method has been shown to help a learner respond better in a learning environment. The participants in the optical microscopy group in this present research had previously used optical microscopes during their formally scheduled practical histology sessions, and this could have facilitated them in learning the Histology of the Eye. Conversely, the virtual microscope was a new learning resource for the virtual microscopy group participants. Despite the insignificant difference, it is 
noteworthy to highlight that students' learnability of the virtual microscopy group could be substantially better than those of the optical microscopy group as those of the virtual microscopy group went through a new learning environment. Having the aim to be at par with their counterparts in the optical microscopy group, participants in the virtual microscopy group indicated that they were adapting very well to the learning process, although they had to spend more time familiarising themselves with the tool.

In addition to the knowledge acquisition measure, the present study also revealed that students had a positive perception of the usability of virtual microscopy as a learning tool, evidenced by the significantly higher satisfaction score. Although several past studies have recorded students' opinions, there is still insufficient data drawn from a direct measurement of students' level of satisfaction towards virtual microscopy or optical microscopy. A study by Hande et al. measured student satisfaction with the use of the optical microscope, virtual microscope and both optical and virtual microscopes (24). The study showed a very high degree of satisfaction (87.61\%) towards virtual microscope usage in learning (24). Several other studies explored students' opinions towards the use of virtual microscopy. Overall, these studies reported several advantages of using a virtual microscope as a learning tool, namely easy navigation with optimum contrast, clear solutions for issues related to tissue section variability, presence of interactive features that allow collaborative learning and easy access to virtual microscopy during the self-study period $(9,25,30,32,36-37)$. However, it should be noted that some students and educators had also indicated a strong preference for continued use of traditional microscopy, supplemented with virtual microscopy, as both tools in adjunct optimised students' learning (38-39).

\section{LIMITATIONS AND RECOMMENDATION}

The generalisability of this study's results is subjected to two limitations. The most important limitation lies in the fact that it has a small sample size as a result of a high dropout rate, which was $23.7 \%$. Nevertheless, the high dropout rate was not due to the research intervention; rather, it was due to an external factor as most of the dropout subjects had attended a university event that was scheduled after the intervention date was confirmed. Besides that, the data collection was conducted at a single point in time, whereby the participants had only one-time exposure to the virtual microscopy. Limited exposure to virtual microscopy might not be able to ensure adequate development of cognitive and skill competencies in using the virtual microscopy, and thus, the actual potential of virtual microscopy in enhancing students learning might not be reflected.

Hence, further studies need to be carried out to validate the findings of this study. It would be worthwhile to either include a different cohort of medical students or conduct multicentre studies to address the small sample size issues. Future longitudinal studies should also be conducted to ensure the adequate acquisition of knowledge and skills. Expanding the knowledge acquisition measures, such as retention of knowledge, task transfer and students' motivation and insight can provide a clearer dimension about how virtual microscopy can influence students' learning.

\section{CONCLUSION}

In summary, this study identified virtual microscopy as a potential learning tool in histology teaching. Although similar knowledge was acquired from virtual and 
optical microscopy, the study samples indicated a higher level of satisfaction in learning by using virtual microscopy. The current COVID-19 pandemic situation has given rise to online teaching and learning in the lifeline of education delivery. Hence, exploring the impacts of virtual microscopy on students learning from different angles has been beneficial to establish the role of virtual microscopy in the ensuring effective delivery of effective education.

\section{ETHICAL APPROVAL}

This study obtained ethical approval from the Human Research Ethics Committee of Universiti Sains Malaysia (JEPeM) USM/ JEPeM/15100338).

\section{ACKNOWLEDGEMENTS}

The authors would like to thank Universiti Sains Malaysia (USM Short Term Grant [304/PPSP/61313040]) for enabling us to conduct this research at their institution and for providing funding for this research. We would also like to thank the supporting staff of the School of Medical Sciences' Department of Anatomy, who provided the technical support required throughout the research. Finally, we would like to extend our deepest gratitude to the pre-clinical medical students who volunteered for this research.

\section{REFERENCES}

1. Hajj Hussein I, Raad M, Safa R, Jurjus $\mathrm{R}$, Jurjus A. Once upon a microscopic slide: the story of histology. J Cytol Histol. 2015;6:377. https://doi.org/10.4172/21577099.1000377

2. Aziz Hussin A. Education 4.0 made simple: ideas for teaching. Int J Educ Lit Stud. 2018;6(3):92-8. https://doi.org/10.7575/ aiac.ijels.v.6n.3p.92
3. Hortsch M. Virtual biology: teaching histology in the age of Facebook. FASEB J. 2013 Feb;27(2):411-3. https://doi. org/10.1096/fj.13-0201ufm

4. Drake RL. A retrospective and prospective look at medical education in the United States: trends shaping anatomical sciences education. J Anat. 2014;224(3):256-60. https://doi.org/10.1111/joa.12054

5. Blake CA, Lavoie HA, Millette CF. Teaching medical histology at the University of South Carolina School of Medicine: transition to virtual slides and virtual microscopes. Anat Rec B New Anat. 2003;275(1):196-206. https://doi. org/10.1002/ar.b.10037

6. Braun MW, Kearns KD. Improved learning efficiency and increased student collaboration through use of virtual microscopy in the teaching of human pathology. Anat Sci Educ. 2008;1(6):240-6. https://doi.org/10.1002/ase.53

7. Husmann PR, O'Loughlin VD, Braun MW. Quantitative and qualitative changes in teaching histology by means of virtual microscopy in an introductory course in human anatomy. Anat Sci Educ. 2009;2(5):218-26. https://doi.org/10.1002/ ase. 105

8. Dee FR. Virtual microscopy in pathology education. Hum Pathol. 2009; 40(8):1112-21. https://doi.org/10.1016/j. humpath.2009.04.010

9. Ordi O, Bombí JA, Martínez A, Ramírez J, Alòs L, Saco A, et al. Virtual microscopy in the undergraduate teaching of pathology. J Pathol Inform. 2015;6:1. https://doi. org/10.4103/2153-3539.150246

10. Gurcan MN, Boucheron LE, Can A, Madabhushi A, Rajpoot NM, Yener B. Histopathological image analysis: a review. IEEE Rev Biomed Eng. 2009;2:147-71. https://doi.org/10.1109/ RBME.2009.2034865 
11. Morales CR. Teaching digital histology. In: Mendez-Vilas A, editor. Current microscopy contributions to advances in science and technology, Vol. 2. Badajoz: Formatex Research Center; 2012. p. 994-8.

12. Mione $S$, Valcke $M$, Cornelissen $M$. Evaluation of virtual microscopy in medical histology teaching. Anat Sci Educ. 2013;6(5):307-15. https://doi.org/10.1002/ ase. 1353

13. Tian Y, Xiao W, Li C, Liu Y, Qin M, Wu Y, et al. Virtual microscopy system at Chinese medical university: an assisted teaching platform for promoting active learning and problem-solving skills. BMC Med Educ. 2014;14:74. https://doi.org/10.1186/14726920-14-74

14. Hadie SNH, Hassan A, Mohd Ismail ZI, Ismail HN, Talip SB, Abdul Rahim AF. Empowering students' minds through a cognitive load theory-based lecture model: a metacognitive approach. Innov Educ Teach Int. 2018;55(4):398-407. https://doi.org/10. 1080/14703297.2016.1252685

15. Wagner K, Klein M, Klopp E, Puhl T, Stark R. Effects of instruction-supported learning with worked examples in quantitative method training. High Educ Stud. 2013;3:112. https://doi.org/10.5539/hes.v3n3p1

16. Ogu E, Adekunle Y. Basic concepts of expert system shells and an efficient model for knowledge acquisition. Int J Sci Res. 2013;2(4):554-9.

17. Bingham CB, Kahl SJ. The process of schema emergence: assimilation, deconstruction, unitization and the plurality of analogies. Acad Manag J. 2012;56(1):1434. https://doi.org/10.5465/amj.2010.0723

18. Gardiner JM, Gawlik B, RichardsonKlavehn A. Maintenance rehearsal affects knowing, not remembering; elaborative rehearsal affects remembering, not knowing. Psychon Bull Rev. 1994;1(1):107-10. https://doi.org/10.3758/BF03200764
19. Myers DG. Stress and health. In: Exploring psychology. 6th ed. New York: Worth Publishers; 2005. p. 402.

20. Ammons RB. Effects of knowledge of performance: a survey and tentative theoretical formulation. J Gen Psychol. 1956;54(2):279-99. https://doi.org/10.1080/ 00221309.1956 .9920284

21. Taylor J, Furnham A, editors. Learning quotient. In: Learning at work. London: Palgrave Macmillan; 2005. https://oi. org/10.1057/9780230505650

22. Weerasinghe IMS, Lalitha R, Fernando S. Students' satisfaction in higher education literature review. Am J Educ Res. 2017;5(5):533-9.

23. Dhaqane $M$, Afrah N. Satisfaction of students and academic performance in Benadir University. Journal of Education and Practice. 2016;7(24):59-63.

24. Hande AH, Lohe VK, Chaudhary MS, Gawande MN, Patil SK, Zade PR. Impact of virtual microscopy with conventional microscopy on student learning in dental histology. Dent Res J (Isfahan). 2017;14(2):111-6.

25. Krippendorf BB, Lough J. Complete and rapid switch from light microscopy to virtual microscopy for teaching medical histology. Anat Rec B New Anat. 2005;285(1):19-25. https://doi.org/10.1002/ar.b.20066

26. Noda K, Nunome T, Tasaka S, Fukaya K. Assessment of educational effectiveness in real-time distance lectures over IP networks. In: 2009 15th Asia-Pacific Conference on Communications. 2009. p. 862-5. https:// doi.org/10.1109/APCC.2009.5375466

27. Social Science Statistics [Internet]. Effect size calculator for t-test; c2015 [cited 2018 March 1]. Available from: http://www. socscistatistics. com/effectsize/Default3.aspx

28. Cohen J. Statistical power analysis for the behavioural sciences. 2nd ed. New Jersey: Lawrence Erlbaum Associates; 1988. 
29. Felszeghy S, Pasonen-Seppänen S, Koskela A MA. Student-focused virtual histology education: do new scenarios and digital technology matter? MedEdPublish. 2017;6(3):40. https://doi.org/10.15694/ mep.2017.000154

30. Nauhria S, Ramdass PVAK. Randomized cross-over study and a qualitative analysis comparing virtual microscopy and light microscopy for learning undergraduate histopathology. Indian J Pathol Microbiol. 2019;62(1):84-90. https://doi.org/10.4103/ IJPM.IJPM_241_18

31. Scoville SA, Buskirk TD. Traditional and virtual microscopy compared experimentally in a classroom setting. Clin Anat. 2007;20(5):565-70. https://doi.org/10.1002/ ca. 20440

32. Donnelly AD, Mukherjee MS, Lyden ER, Radio SJ. Virtual microscopy in cytotechnology education: application of knowledge from virtual to glass. Cytojournal. 2012;9:12. https://doi. org/10.4103/1742-6413.95827

33. Kaba A, Ramaiah C. Measuring knowledge acquisition and knowledge creation: a review of literature. Libr Philos Pract [Internet]. 2019 Apr 25;4723. Available from: https:// digitalcommons.unl.edu/libphilprac/4723

34. Davies M. Knowledge (explicit, implicit and tacit): philosophical aspects. In: Wright JD, editor. International Encyclopedia of the Social \& Behavioral Sciences. Oxford: Elsevier; 2015. p. 74-90. https://doi. org/10.1016/B978-0-08-097086-8.63043-X
35. Ericsson K, Krampe R, Tesch-Roemer C. The role of deliberate practice in the acquisition of expert performance. Psychol Rev. 1993;100:363-406. https://doi. org/10.1037/0033-295X.100.3.363

36. Helle L, Nivala $M$, Kronqvist P, Gegenfurtner A, Björk P, Säljö R. Traditional microscopy instruction versus process-oriented virtual microscopy instruction: a naturalistic experiment with control group. Diagn Pathol. 2011;6(Suppl 1):S8. https://doi.org/10.1186/1746-1596-6S1-S8

37. Saco A, Bombi JA, Garcia A, Ramírez J, Ordi J. Current status of whole-slide imaging in education. Pathobiology. 2016;83(2-3):79-88. org/10.1159/000442391

38. Neel JA, Grindem CB, Bristol DG. Introduction and evaluation of virtual microscopy in teaching veterinary cytopathology. J Vet Med Educ. 2007;34(4):437-44. https://doi.org/10.3138/ jvme.34.4.437

39. $\mathrm{Xu} \mathrm{C-J.} \mathrm{Is} \mathrm{virtual} \mathrm{microscopy} \mathrm{really} \mathrm{better}$ for histology teaching? Anat Sci Educ. 2013;6(2):138. https://doi.org/10.1002/ ase. 1337 